\title{
Desenvolvimento foliar e sincronismo dos afilhos na cultivar de arroz 'IRGA 417'
}

\author{
Leaf development and tiller synchronism in rice cultivar 'IRGA 417'
}

\author{
Naracelis Poletto $^{\mathrm{I}^{*}}$ Claudio Mario Mundstock ${ }^{\mathrm{I}}$ Daniel Santos Grohs ${ }^{\mathrm{II}}$ \\ Alexandre Tadeu Piana' Michael Mazurana ${ }^{\mathrm{III}}$
}

\section{RESUMO}

\begin{abstract}
O sincronismo de emissão e desenvolvimento de folhas entre o colmo principal e afilhos é determinante para a sobrevivência dessas estruturas durante o ciclo de cultivo do arroz. O presente trabalho teve como objetivos estudar o desenvolvimento foliar do colmo principal e dos afilhos na cultivar de arroz 'IRGA 417' $e$ identificar a ocorrência de sincronismo entre esses dois processos durante o estádio vegetativo, utilizando a escala de desenvolvimento proposta por HAUN (1973). O experimento foi conduzido em sistema hidropônico, e as plantas foram cultivadas até o início do desenvolvimento da oitava folha do colmo principal (22 dias após o transplante). A emergência da primeira folha de cada afilho foi retardada e quase coincidiu com a emissão da segunda folha. A emergência do primeiro e do segundo afilho foi concomitante e iniciou quando as plantas estavam com 3.9 unidades Haun, estendendo-se até o estádio 5.1 da escala de Haun. Já a emissão do terceiro e do quarto afilho foi posterior e ocorreu quando as plantas apresentavam, em média, 6.0 e 7.0 unidades Haun, respectivamente. O sincronismo ocorreu apesar da emissão tardia da primeira folha dos afilhos, e o percentual de afilhos sincronizados aumentou com o avanço do desenvolvimento foliar do colmo principal.
\end{abstract}

Palavras-chave: colmo principal, afilho, desenvolvimento foliar.

\section{ABSTRACT}

Synchronism of leaf development between main stem and tillers has a strong influence on tillers surviving, mainly on early stages plant cycle in rice. Leaf development in rice cultivar 'IRGA 417' was studied to identify synchronism between tillers and main stem on early vegetative period using the growth stages as proposed by HAUN (1973). Plants were grown in hydroponic system until the main stem eighth leaf (22 days after transplant). First leaf appearance of each primary tiller was delayed and almost coincided with the emergence of second leaf. First and second tillers appearance were concomitant and began when the plants were on the stage 3.9 (HAUN, 1973). Third and fourth tillers appeared later when the plants were, on average, on stage 6.0 and 7.0 (HAUN, 1973), respectively. Synchronism, characterized by the difference between number of leaves of main stem and tillers, occurred despite the late emergence of the tillers' first leaf, and the percentage of synchronized tillers increased along with the main stem leaf development.

Key words: main stem, tiller, leaf development.

\section{INTRODUÇÃO}

O processo de emissão externo das folhas do colmo principal e dos afilhos é interligado e associado à taxa de emergência foliar e à época de iniciação de afilhos. A interligação entre a taxa de emissão de folhas pelo colmo principal e a taxa de emissão de folhas pelos afilhos é definida como sincronismo (HANADA, 1993; JAFFUEL \& DAUZAT, 2005). A ocorrência de sincronismo durante a emergência e o desenvolvimento foliar de cada afilho com o colmo principal tem sido observada em estudos conduzidos em arroz (HANADA, 1993; NEMOTO, 1995; JAFFUEL \& DAUZAT, 2005).

O afilhamento em arroz é um processo complexo (LI et al., 2003), e a compreensão do processo passa pelo entendimento do crescimento foliar e de

\footnotetext{
IPrograma de Pós-graduação em Fitotecnia, Faculdade de Agronomia, Universidade Federal do Rio Grande do Sul (UFRGS). Av. Bento Gonçalves, 7712, 91501-970, Porto Alegre, RS, Brasil. E-mail: narapoletto@gmail.com.*Autor para correspondência. IIInstituto Riograndense do Arroz (IRGA), Cachoeirinha, RS, Brasil.

IIICurso de agronomia, Faculdade de Agronomia, UFRGS, Porto Alegre, RS, Brasil.
} 
sua morfologia (JAFFUEL \& DAUZAT, 2005). A rapidez na exteriorização dos afilhos é fundamental para a sua sobrevivência e é determinante para a produção de panículas (MILLER et al., 1991) e para o rendimento final de grãos (GALLAGHER \& BISCOE, 1978). Os afilhos potencialmente produtivos, normalmente, são aqueles emitidos precocemente e que se mantêm, ao longo do ciclo de cultivo, em sincronia com o desenvolvimento do colmo principal (RAWSON, 1971; KIRBY \& RIGGS, 1978; MASLE, 1985). Apesar da importância da quantificação e descrição da interrelação do desenvolvimento foliar do colmo principal e seus respectivos afilhos ao longo do ciclo de desenvolvimento das plantas, a maioria dos trabalhos conduzidos em arroz no Brasil não descrevem detalhadamente esse processo.

O estudo concomitante do desenvolvimento foliar do colmo principal e dos afilhos pode ser feito com a utilização da escala de desenvolvimento proposta por HAUN (1973) (descrição do desenvolvimento de cada colmo) e ampliada por KLEPPER et al. (1982) (descrição dos afilhos). Ela tem sido utilizada para descrever o desenvolvimento foliar do colmo principal em arroz (et al., 2007; STRECK et al., 2008) e vem sendo progressivamente adotada em práticas de manejo (MUNDSTOCK, 1999). Essa escala permite o estudo do desenvolvimento foliar do colmo principal e de cada afilho individualmente ao longo do tempo, de forma simples, direta e não destrutiva (MUNDSTOCK, 1999), verificando o sincronismo desse processo. Por esse estudo, amplia-se o conhecimento da produtividade potencial da lavoura, adequando práticas culturais, como o manejo do nitrogênio, contribuindo para a melhor utilização de recursos disponibilizados e a potencialização dos resultados.
O presente trabalho teve como objetivos estudar o desenvolvimento foliar do colmo principal e dos afilhos na cultivar de arroz 'IRGA 417' e identificar a ocorrência de sincronismo entre esses dois processos durante o estádio vegetativo da cultura, utilizando a escala de desenvolvimento proposta por HAUN (1973).

\section{MATERIAL E MÉTODOS}

O estudo foi conduzido em casa de vegetação, nas dependências da Faculdade de Agronomia da Universidade Federal do Rio Grande do Sul (UFRGS), localizada no Município de Porto Alegre, Rio Grande do Sul (RS), utilizando-se a cultivar de arroz 'IRGA 417'. As plantas foram cultivadas em sistema hidropônico até o início do desenvolvimento da oitava folha do colmo principal, totalizando 22 dias (29/11/ 2007 a 21/12/2007) após o transplante.

As sementes de arroz foram colocadas a germinar por 72 horas, com temperatura de $24^{\circ} \mathrm{C}\left( \pm 2^{\circ} \mathrm{C}\right)$. As plântulas obtidas foram selecionadas de acordo com a uniformidade do comprimento do coleóptilo $( \pm 1 \mathrm{~cm})$ (Figura 1A) e transplantadas para um sistema hidropônico, constituído por bandejas de plástico (2,5L) com capacidade para o cultivo de nove plantas. As plantas, em cada bandeja, foram mantidas suspensas por meio de uma chapa de isopor.

Os macro e micronutrientes foram fornecidos por meio de solução nutritiva conforme HOAGLAND \& ARNON (1938). A reposição da solução nutritiva foi realizada a cada 72 horas nas primeiras duas semanas de cultivo e a cada 48 horas nas demais. $\mathrm{O}$ pH da solução nutritiva foi mantido entre 5,5 e 6,5 e medido diariamente e reajustado com a utilização de $\mathrm{KOH}\left(0,10 \mathrm{~mol} \mathrm{~L}^{-1}\right)$ ou $\mathrm{H}_{2} \mathrm{SO}_{4}\left(0,05 \mathrm{~mol} \mathrm{~L}^{-1}\right)$. Atemperatura máxima (valores entre

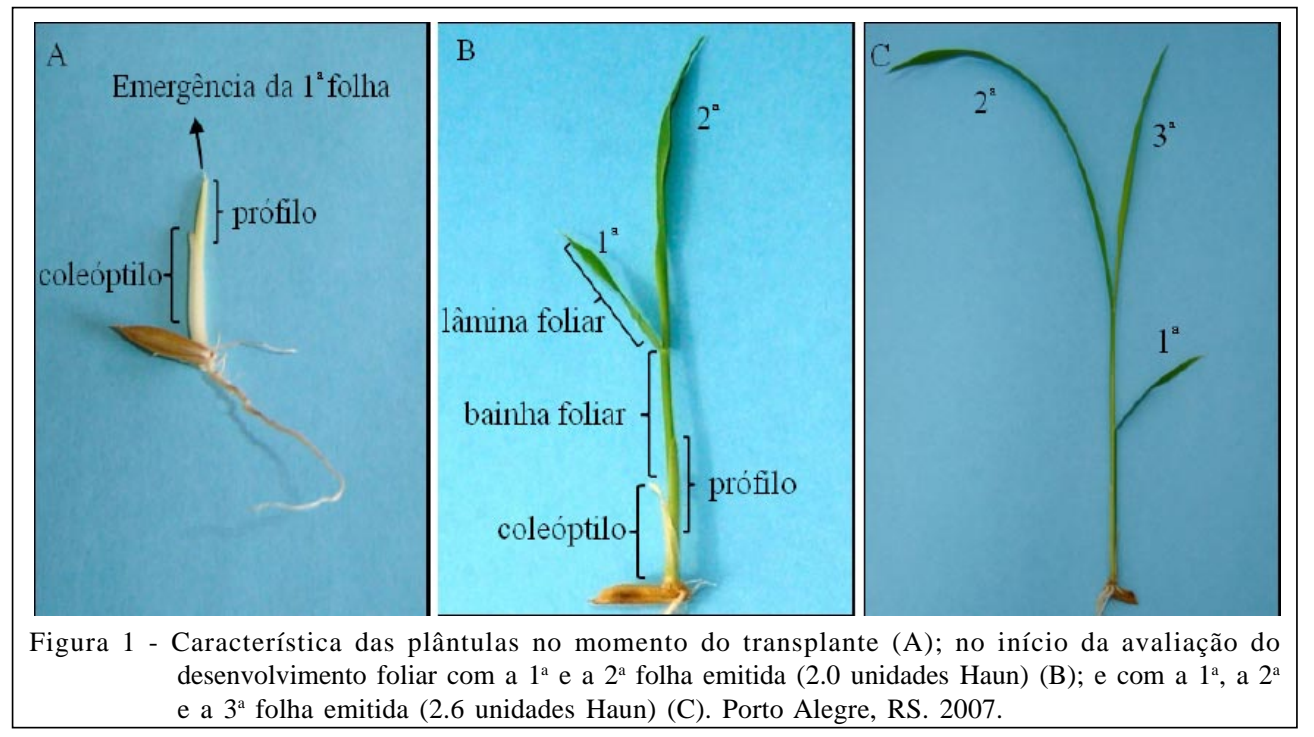

Ciência Rural, v.39, n.8, nov, 2009. 
32 e $41^{\circ} \mathrm{C}$ ) e a mínima (valores entre 17 e $25^{\circ} \mathrm{C}$ ) da casa de vegetação foi monitorada diariamente.

As avaliações foram realizadas diariamente por meio da observação visual de 54 plantas (18 plantas distribuídas em três repetições) durante o período experimental. O desenvolvimento foliar do colmo principal e dos afilhos primários (primeiro afilho $\left(\mathrm{A}_{1}\right)$, segundo afilho $\left(A_{2}\right)$, terceiro afilho $\left(A_{3}\right)$ e quarto afilho $\left(\mathrm{A}_{4}\right)$ ) originados na base das quatro primeiras folhas do colmo principal foi avaliado utilizando-se a escala de desenvolvimento foliar proposta por HAUN (1973) e ampliada por KLEPPER et al. (1982) para descrição dos afilhos. Nessa escala, as folhas são numeradas em ordem acrópeta. O número de folhas totalmente expandidas, mais as unidades decimais da última folha do colmo principal que está em expansão, fornecem o valor do estádio fenológico denominado no texto como “unidades Haun”. Assim, uma planta no estádio 6.1 da escala Haun (6.1 unidades Haun) tem a sexta folha completamente expandida e a sétima com um décimo do comprimento da sexta. A partir da escala Haun, foi possível determinar o sincronismo entre o desenvolvimento do colmo principal e dos afilhos emitidos. O sincronismo de desenvolvimento dos afilhos com o colmo principal foi calculado seguindo o padrão de desenvolvimento do colmo principal e dos afilhos descrito por MASLE (1985). Os afilhos considerados sincronizados com o desenvolvimento do colmo principal foram aqueles que apresentaram diferença de até três $\left(A_{1}\right)$, quatro $\left(A_{2}\right)$, cinco $\left(A_{3}\right)$ e seis $\left(\mathrm{A}_{4}\right)$ unidades Haun com o colmo principal. Assim, os afilhos $A_{1}, A_{2}, A_{3}$ e $A_{4}$ eram considerados sincronizados com o desenvolvimento do colmo principal de uma planta com 6.1 unidades Haun quando estes apresentavam no mínimo 3.1, 2.1, 1.1 e 0.1 unidades Haun, respectivamente.

\section{RESULTADOS E DISCUSSÃO}

Desenvolvimento foliar do colmo principal

A observação do desenvolvimento foliar do colmo principal iniciou com a emergência do prófilo, após a saída do coleóptilo (Figura 1A), como descrito por COUNCE et al. (2000). O prófilo não foi considerado como folha verdadeira (na contagem de folhas emitidas pelo colmo principal) em razão da sua distinta morfologia (formado somente pela bainha foliar). As demais folhas eram constituídas de bainha e lâmina foliar e foram emitidas acima do prófilo (Figuras 1B e 1C).

O desenvolvimento foliar do colmo principal (Figura 2A) foi muito rápido, provavelmente em razão da ocorrência de altas temperaturas (acima de $35^{\circ} \mathrm{C}$ ) na casa de vegetação. Os estudos de FREITAS et al. (2006) para a mesma cultivar de arroz ('IRGA 417') durante período similar de cultivo, e também os trabalhos de COUNCE et al. (2000) e JAFFUEL \& DAUZAT (2005) indicam que a temperatura é um dos principais fatores reguladores da taxa de emissão foliar. Isso também foi observado por KINIRY et al. (1991) e SLAFER et al. (1994), pois o incremento na temperatura, principalmente acima de $30^{\circ} \mathrm{C}$, intensificou o processo de desenvolvimento de folhas pelo colmo principal e pelos afilhos em plantas de arroz (YIN \& KROPFF, 1996).

\section{Desenvolvimento foliar dos afilhos}

A primeira folha de cada afilho foi emitida com atraso, pois seu filocrono é maior que o das folhas subsequentes (NEMOTO, 1995). Isso ocasionou a emissão concomitante da primeira e da segunda folha nos afilhos $\mathrm{A}_{1}, \mathrm{~A}_{2}$ e $\mathrm{A}_{3}$, como ilustrado nas Figuras 3A, 3B e 3C, respectivamente. Assim, a primeira folha do primeiro afilho emergiu quando o colmo principal estava no estádio Haun de 3.9 unidades (Figura 2A), caracterizando uma emissão tardia da primeira folha em comparação com o padrão de emissão de afilhos descrito para cereais de inverno (MASLE, 1985; SKINNER \& NELSON, 1994). O intervalo de tempo observado entre a emissão das folhas subsequentes à primeira foi normal, pois, para cada filocrono do afilho, correspondeu aproximadamente um filocrono do colmo principal.

\section{Sincronismo dos afilhos}

A emergência dos dois primeiros afilhos (Figuras 2A e 2B) foi concomitante. Dentre as plantas amostradas, a emissão do $\mathrm{A}_{1}$ iniciou quando o colmo principal estava com 3.9 unidades Haun. No primeiro dia, $60 \%$ das plantas estavam com o $\mathrm{A}_{1}$ emitido (Figuras 2A e 2B), e o processo se estendeu por um período de mais dois dias, quando o colmo principal das plantas já estava no estádio 4.7 da escala Haun (Figura 2B). Ao final do processo de emergência do $A_{1}$, a maioria das plantas (aproximadamente 70\%) já havia emitido também o $\mathrm{A}_{2}$ (Figuras 2B). A emergência de dois afilhos em praticamente o mesmo estádio de desenvolvimento do colmo principal em plantas de arroz também foi constatada por JAFFUEL \& DAUZAT (2005). Nos afilhos seguintes, $A_{3}$ e $A_{4}$, a emissão foi posterior e iniciou quando as plantas apresentavam, em média, 6.0 e 7.0 unidades Haun, respectivamente (Figuras 2A e 2B).

A planta sincronizada foi assim considerada quando a diferença entre o número de folhas emitidas pelo colmo principal e pelos afilhos se manteve em até três (para o $\mathrm{A}_{1}$ ), quatro (para o $\mathrm{A}_{2}$ ), cinco (para o $\mathrm{A}_{3}$ ) e seis (para o $\mathrm{A}_{4}$ ) unidades Haun (Figuras 2A e 4). Os 


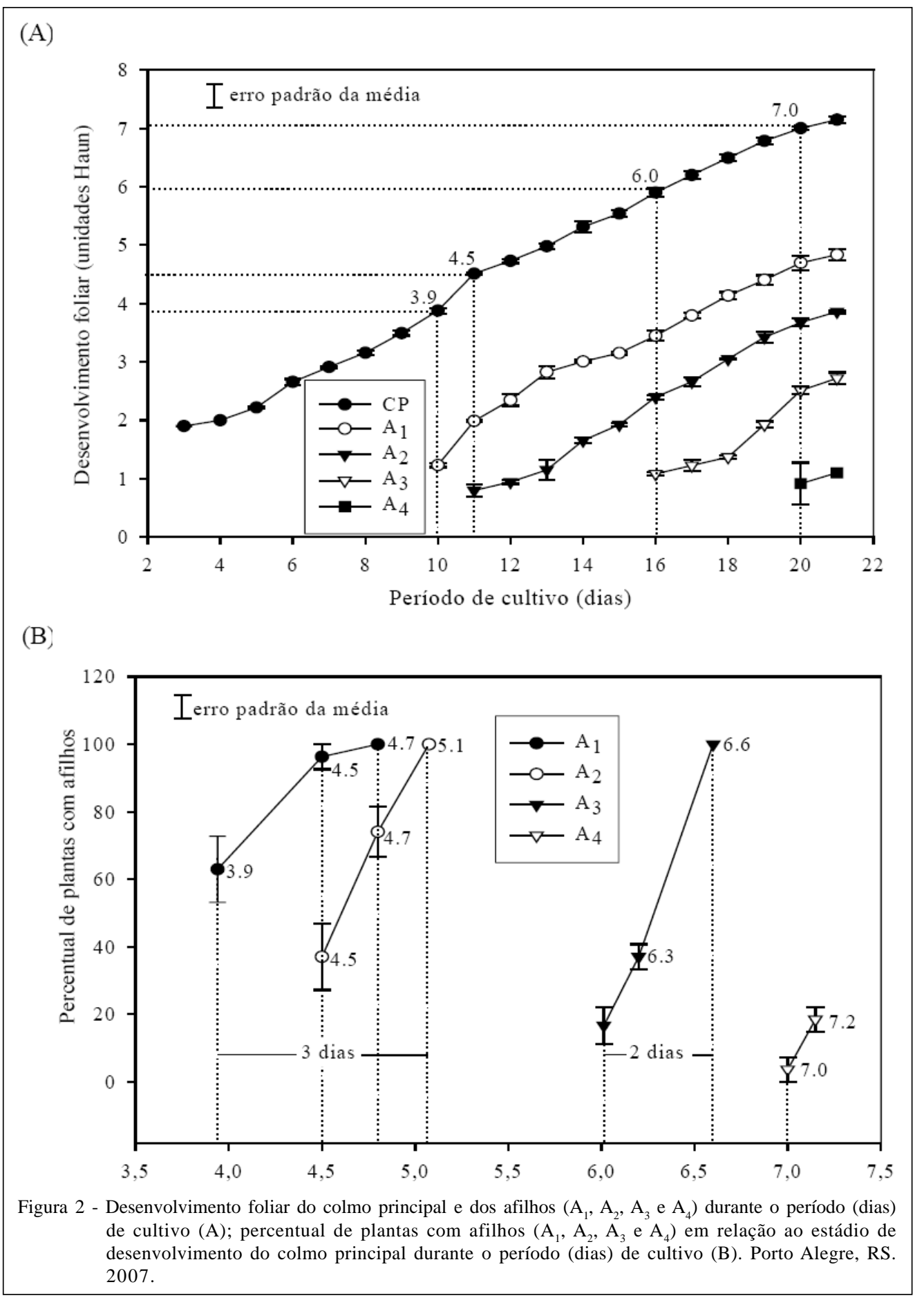

valores descritos anteriormente foram alcançados apesar da emissão tardia da primeira folha dos afilhos, mas a emissão conjunta da segunda folha com a primeira permitiu à planta manter o sincronismo. As 54 plantas amostradas emitiram os afilhos $\mathrm{A}_{2}$ e $\mathrm{A}_{3}$ em curto espaço de tempo. $\mathrm{O}$ afilho $\mathrm{A}_{2}$ começou a ser emitido quando as plantas tinham 4.5 unidades Haun e terminou quando o colmo principal estava com 5.1 unidades Haun (0.6 unidades Haun de diferença). Situação similar ocorreu com o $\mathrm{A}_{3}$, que iniciou com 6.0 unidades Haun do colmo principal e finalizou com 6.6 unidades Haun do colmo principal (diferença de 0,6 unidades Haun) (Figura 2B). Para o sincronismo de desenvolvimento foliar entre os afilhos e o colmo principal (Figuras 2A, 


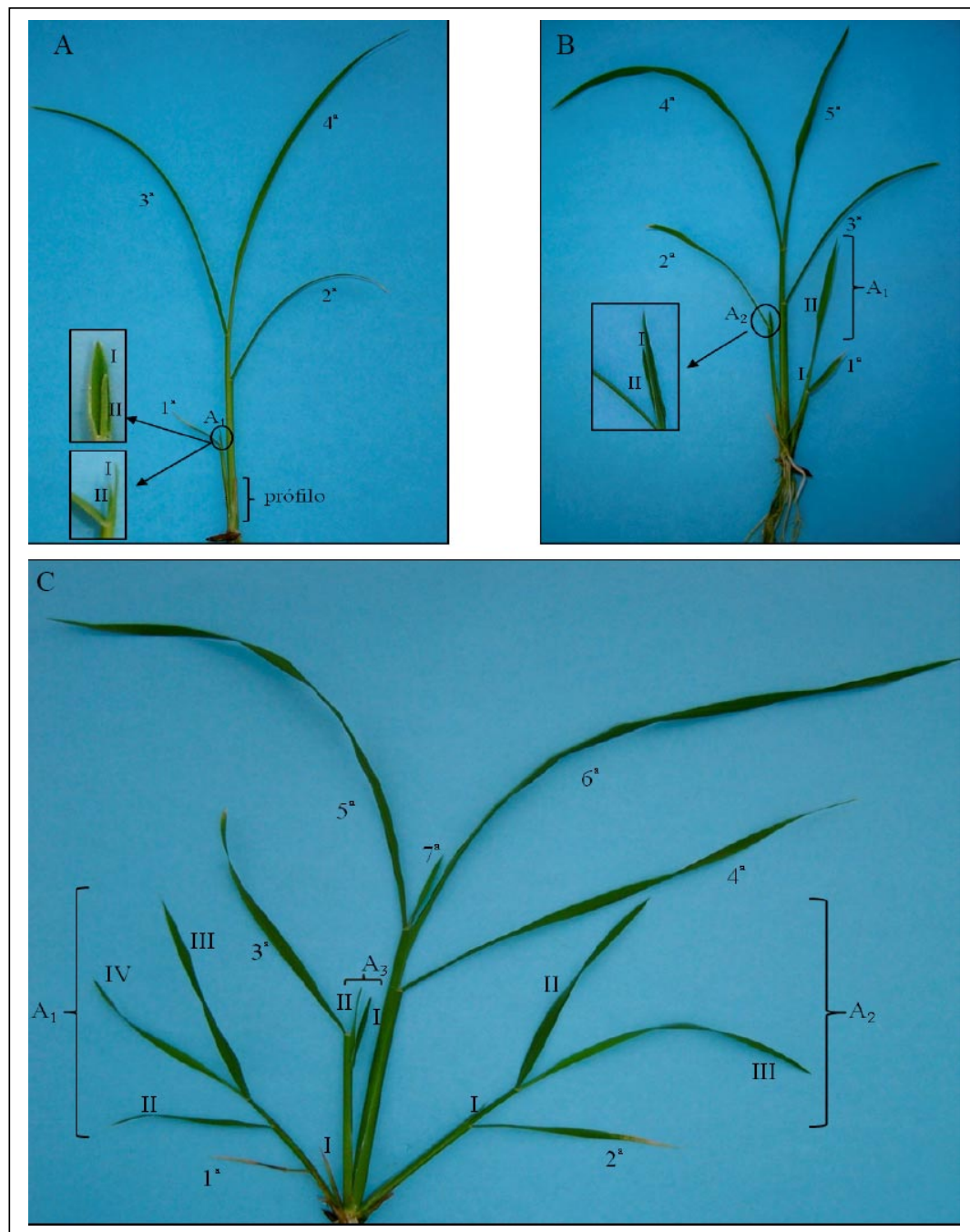

Figura 3 - Desenvolvimento foliar do colmo principal (4.0 unidades Haun) (representado em números arábicos) e emissão concomitante das primeiras duas folhas do afilho $\mathrm{A}_{1}$ (1.1 unidades Haun) (representado em números romanos) (A); desenvolvimento foliar do colmo principal (4.6 unidades Haun), $\mathrm{A}_{1}$ (2.0 unidades Haun) e a emissão concomitante das primeiras duas folhas do $\mathrm{A}_{2}$ (1.1 unidades Haun) (B); desenvolvimento foliar do colmo principal (6.1 unidades Haun), $A_{1}$ (3.9 unidades Haun), $A_{2}$ (3.0 unidades Haun) e a emissão concomitante das primeiras duas folhas do $\mathrm{A}_{3}$ (1.1 unidades Haun) (C) durante 17 dias de cultivo. Porto Alegre, RS. 2007.

4 e 5), provavelmente contribuiu o fato de que as folhas dos afilhos possuem menor filocrono (maior taxa de desenvolvimento foliar), da ordem de 10\% (NEMOTO, 1995), em relação às folhas do colmo principal durante o estádio vegetativo (HANADA, 1993; JAFFUEL \& DAUZAT, 2005). O sincronismo no desenvolvimento foliar entre colmo principal e afilhos (HANADA, 1993; NEMOTO, 1995; JAFFUEL \& DAUZAT, 2005) é fundamental para a sobrevivência dos afilhos e a produção de panículas (NEMOTO, 1995). Quando há limitação de recursos externos como, a luz e os nutrientes há o aumento do filocrono nos afilhos em relação ao colmo principal. O atraso na taxa de desenvolvimento foliar resulta em sua morte, na redução do número de inflorescências área ${ }^{-1}$ e, consequentemente, no rendimento de grãos (HANADA, 1993; NEMOTO, 1995; MUNDSTOCK \& BREDEMEIER, 2001).

O acompanhamento detalhado do desenvolvimento foliar do colmo principal e dos afilhos por meio da escala de Haun durante a condução da lavoura de arroz poderá auxiliar técnicos e extensionistas na determinação da melhor época para aplicação de práticas culturais, como a aplicação de

Ciência Rural, v.39, n.8, nov, 2009. 


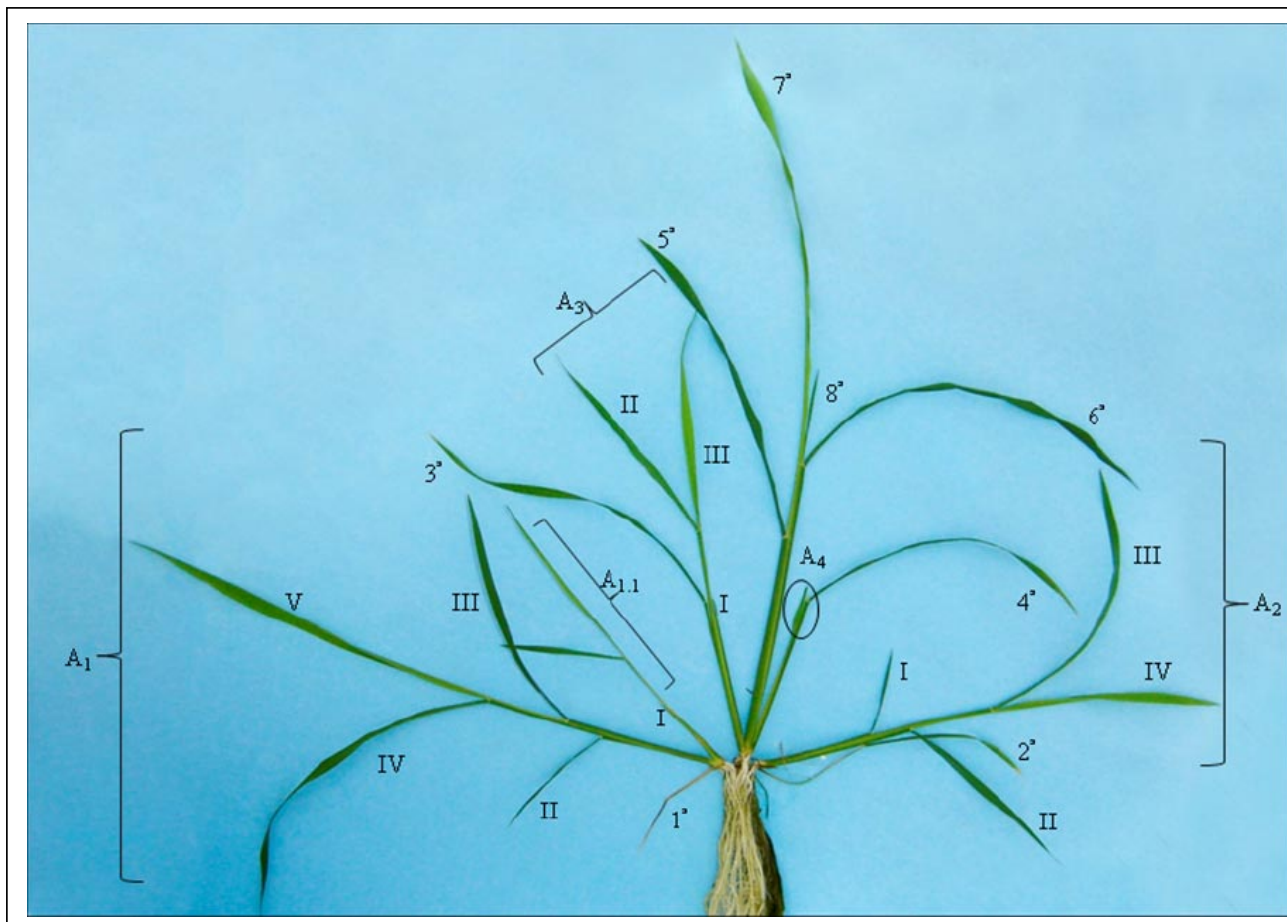

Figura 4 - Desenvolvimento foliar do colmo principal (7.1 unidades Haun) (representado em números arábicos) e dos afilhos (representado em números romanos) $A_{1}$ (5.0 unidades Haun), $A_{2}$ (4.0 unidades Haun), $\mathrm{A}_{3}$ (3.0 unidades Haun) e emissão do $\mathrm{A}_{4}$ (0.1 unidades Haun) durante 22 dias de cultivo. Porto Alegre, RS. 2007.

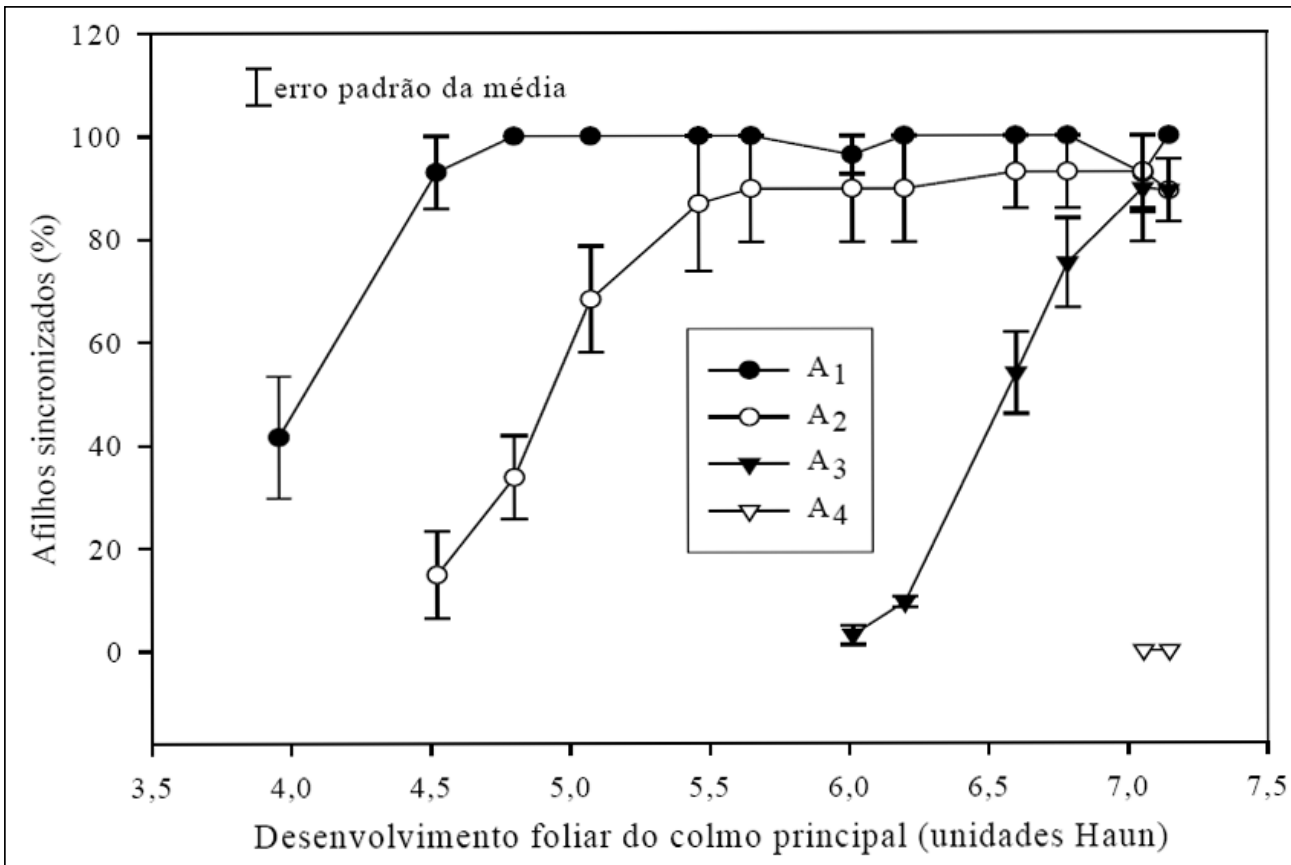

Figura 5 - Percentual de afilhos $\left(A_{1}, A_{2}, A_{3}\right.$ e $\left.A_{4}\right)$ com desenvolvimento foliar em sincronia com o desenvolvimento foliar do colmo principal. (\% de cada afilho $\left(A_{1}, A_{2}, A_{3}\right.$ e $\left.A_{4}\right)$ sincronizado $=$ (número total de cada afilho em sincronia com o desenvolvimento do colmo principal/ número total de cada afilho emitido) x 100). Porto Alegre, RS. 2007.

Ciência Rural, v.39, n.8, nov, 2009. 
nitrogênio. Nesse caso específico, a aplicação de nitrogênio poderá ser feita visando à manutenção do sincronismo de desenvolvimento entre os afilhos emitidos e o colmo principal. Isso, por sua vez, pode potencializar a sobrevivência do maior número de afilhos, contribuindo para o incremento do número de panículas por área e do rendimento final de grãos.

\section{CONCLUSÕES}

A escala de desenvolvimento de HAUN (1973) é eficiente para caracterizar os eventos de emissão e desenvolvimento foliar do colmo principal e dos afilhos na cultivar de arroz 'IRGA 417'.

O sincronismo, caracterizado pela diferença entre o número de folhas emitidas pelo colmo principal e pelos afilhos, ocorre apesar da emissão tardia da primeira folha dos afilhos, e o percentual de afilhos sincronizados aumenta com o avanço do desenvolvimento foliar do colmo principal.

A emissão da primeira folha de cada afilho é retardada, mas isso não prejudica o sincronismo dos afilhos com o colmo principal devido à rápida emissão da segunda folha.

\section{REFERÊNCIAS}

COUNCE, P.A. et al. A uniform, objective, and adaptive system for expressing rice development. Crop Science, Madison, v.40, n.2, p.436-443, 2000. Disponível em: http://crop.scijournals.org/ cgi/content/full/40/2/436\#FN. Último acesso em 30/07/2009.

FREITAS, T.F.S. et al. Validação de escala de desenvolvimento para cultivares brasileiras de arroz irrigado. Ciência Rural, Santa Maria, v.36, n.2, p.404-410, 2006. Disponível em: http://www.scielo.br/ sciel o.php ? script = s ci_art t ext \& pid = S 0103 $84782006000200008 \& \operatorname{lng}=\mathrm{em} \& n r m=$ iso\&tlng=pt. Último acesso em 30/07/2009. doi: 10.1590/S0103-84782006000200008.

GALLAGHER, J.N.; BISCOE, P.V. Radiation absorption, growth and yield of cereals. Journal of Agricultural Science, New York, v.91, n.1, p.47-60, 1978.

HANADA, K. Morphology and development of vegetative organs. 4. Tillers. In: MATSUO, T.; HOSHIKAMA, K. (Ed) Science of the rice plants. Morphology. Tokio: Food and Agricultural Policy Research Center, 1993. V.1, p.222-258.

HAUN, J.R. Visual quantification of wheat development. Agronomy Journal, Madison, v.65, n.1, p.116-119, 1973.

HOAGLAND, D.R.; ARNON, D.I. The water culture method of growing plants without soil. Berkeley: University of California-Agricultural Experiment Station, 1938. 39p. (circular 347).

JAFFUEL, S.; DAUZAT, J. Synchronism of leaf and tiller emergence relative to position and to main stem development stage in a rice cultivar. Annals of Botany, Oxford, v.95, n.3, p.401-412, 2005. Disponível em: http://aob.oxfordjournals.org/ cgi/content/full/95/3/401. Último acesso em 30/07/2009. doi: 10.1093/aob/mci043.
KINIRY, J.R. et al. Predicting leaf development of crop plants. In: HODGES, T. (Ed.). Predicting Crop Phenology. Boca Raton, FL: CRC, 1991. p.29-42.

KIRBY, E.J.M.; RIGGS, T.J. Developmental consequences of two-row and six-row ear type in spring barley: II. Shoot apex, leaf and tiller development. Journal of Agricultural Science, Cambridge, v.91, n.1, p.207-216, 1978.

KLEPPER, B. et al. Quantitative characterization of vegetative development in small grain cereals. Agronomy Journal, Madison, v.74, n.5, p.789-792, 1982

LI, X. et al. Control of tillering in rice. Nature, London, v.422, n.6932, p.618-621, 2003. Disponível em: http:// www.nature.com/nature/journal/v422/n6932/full/ nature01518.html. Último acesso em 30/07/2009. doi: $10.1038 /$ nature 01518 .

MASLE, J. Competition among tillers in winter wheat: consequences for growth and development of the crop. In: DAY, W.; ATKIN, R.K. Wheat growth and modeling. New York: Plenum, 1985. p.33-54.

MILLER, B.C. et al. Plant population effects on growth and yield in water-seeded rice. Agronomy Journal, Madison, v.83, n.2, p.291-297, 1991.

MUNDSTOCK, C.M. Planejamento e manejo integrado da lavoura de trigo. Porto Alegre: Ed. Autor, 1999. 228p.

MUNDSTOCK, C.M; BREDEMEIER, C. Disponibilidade de nitrogênio e sua relação com o afilhamento e o rendimento de grãos de aveia. Ciência Rural, Santa Maria, v.31, n.2, p.205-211, 2001. Disponível em: http://www.scielo.br/ scielo.php? script =sci arttext\&pid=S0103 $84782001000200003 \& \operatorname{lng}=\mathrm{en} \& \mathrm{nrm}=\mathrm{iso} \& \mathrm{t} \operatorname{lng}=\mathrm{pt}$. Último acesso em 30/07/2009. doi: 10.1590/S010384782001000200003 .

NEMOTO, K. et al. Shoot and root development in rice related to the phyllochron. Crop Science, Madison, v.35, n.1, p.2429, 1995.

RAWSON, H.M. Tillering patterns in wheat with special reference to the shoot at the coleoptile node. Australian Journal Biological Sciences, Melbourne, v.25, n.1, p.829841, 1971

SKINNER, R.H.; NELSON, C.J. Epidermal cell division and the coordination of leaf and tiller development. Annals of Botany, London, v.74, n.1, p.9-15, 1994.

SLAFER, G.A. et al. Rate of leaf appearance and final number of leaves in wheat: effects of duration and rate of change of photoperiod. Annals of Botany, London, v.74, n.5, p.427436, 1994.

STRECK, N.A. et al. Filocrono de genótipos de arroz irrigado em função de época de semeadura. Ciência Rural, Santa Maria, v.37, n.2, p.323-329, 2007. Disponível em: http:// www.scielo.br/scielo.php?script $=$ sci arttext \&pid $=$ S0103$84782007000200005 \& \operatorname{lng}=$ en\&nrm=iso\&tlng=pt. Ultimo acesso em 30/07/2009. doi: 10.1590/S0103-84782007000200005.

STRECK, N.A. et al. Simulating leaf appearance in rice. Agronomy Journal, Madison, v.100, n.3, p.490-501, 2008. Disponível em: http://agron.scijournals.org/cgi/content/full/100/ 3/490. Último acesso em 30/07/2009. doi: 10.2134/ agronj2007.0156.

YIN, X.Y.; KROPFF, M.J. The effect of temperature on leaf appearance in rice. Annals of Botany, London, v.77, n.3, p.215-221, 1996

Ciência Rural, v.39, n.8, nov, 2009. 